\title{
Illuminated Furniture as the Atmospheric Factor of Café Interior Design
}

\author{
Prabu Wardono ${ }^{1}$, F.X. Nugroho Soelami² \\ ${ }^{1}$ Faculty of Art and Design, \\ ${ }^{2}$ Faculty of Industrial Engineering, \\ Bandung Institute of Technology, Indonesia \\ pwardono@yahoo.com
}

\begin{abstract}
Behavioral research of lighting is so far limited to that which is set above eye-level. This research project studies the atmospheric effects of illuminated furniture on mood. Using quasi-experimental method, two sets of illuminated furniture were laid out in a café and three different modes of atmospheric qualities resulted were investigated. Seventy student volunteers were asked to join this experiment and report their feelings toward each of those conditions. We used ANOVA statistic to analyze the data. The result shows that the atmospheric quality resulted from a constant setting of illuminated furniture were the most favorable in influencing customer's mood.
\end{abstract}

Keywords: Illuminated furniture; café atmosphere; interior lighting; mood

eISSN 2398-4279 @ 2018. The Authors. Published for AMER ABRA cE-Bs by e-International Publishing House, Ltd., UK. This is an open access article under the CC BY-NC-ND license (http://creativecommons.org/licenses/bync-nd/4.0/). Peer-review under responsibility of AMER (Association of Malaysian Environment-Behaviour Researchers), ABRA (Association of Behavioural Researchers on Asians) and cE-Bs (Centre for EnvironmentBehaviour Studies), Faculty of Architecture, Planning \& Surveying, Universiti Teknologi MARA, Malaysia.

DOI: https://doi.org/10.21834/ajqol.v3i10.101 


\subsection{Introduction}

Human needs sunlight to sustain life. However, excessive exposure to sunlight or lack of its exposure may be harmful to health. According to WHO, healthy individual is achieved when one is physical, mentally and socially well performed. To maintain such condition, people who often feel stress from working or any other daily routine activities would regularly seek places for health restoration. In response to this, researchers or design scientists continually explore prospective elements from the environment including light sources that have the capacity to restore human behavioral problems.

Daylight-human dependency prompts people to keep finding ways in the use of the artificial source of light to create specific effects of light, which can represent the true nature of daylight. This effort is highly relevant for those who are less or not at all exposed to daylight and need a particular quality of lighting to support their daily activities. It may also associate with those who need the restorative effect of light to solve their behavioral problems. Therefore, various approaches to designing lighting effect have been explored to respond to such needs. For instance, people like to see lighted wall surfaces better than being in a lighted area (Veitch, 2001). Essentially, studies on the manipulation of artificial light to create various effects of daylight to expect more positive behavioral responses are becoming crucial. Huge lighting industry like Philips has great interests in developing lighting fixture to replicate various effects of light to meet more complex function of lighting. In fact, mimicking the effects of sunlight with artificial lighting would be one of the numerous challenging tasks, because, its quality may seem countless in number. As well, it is sometimes unpredictable regarding how people can appreciate its presence. Daniel Rybakken, Norwegian young designer's predicts that people sometimes feel the effect of sunlight subconsciously.

In so far, there are no studies that explain whether customers feel differently in response to the effect of lighting on a different location in the room, concerning the client's eye level. This project investigates whether the differentiating location of lighting source in café interiors can affect the observers' moods.

\subsection{Literature Review}

\subsection{Moods as predictor of consumer behavior}

According to McCloughan et al. (1998), moods are defined as subjective expressions of a person's basic feelings at a certain point in time. As people can have good or bad moods, they are not able to explain why this feeling occurs. Therefore, sometimes in such situation people express it interchangeably with affective or emotions.

Some studies relate moods to the way people think, imagine or solve problems. Positive moods are believed to make people think more flexibly and creatively. Complementing this fact, Vosburg (1998) proved that good moods improved subjects' task performance significantly compared with that in bad moods. Since moods can direct and influence what people think, judge and behave in response to anything or environment, questions of what 
factors can change consumer's mood become crucial. This notion is important for café owners, for example, who provide places for people to enjoy foods and drinks need to know how to create an atmosphere, which make people feel good and complement their positive mood. Therefore, although people can be in a bad mood even before they interact with a new environment, we can still expect that it would make people smile and support their mood. Thus, it is relevant to explore the elements of an environment that can please people while performing an activity.

\subsection{Environmental Impact on Mood}

Psychologists found that human effort to reach happiness depends on three of five factors that base human personalities. These factors include: " extraversion (outgoing, active); neuroticism (moody, and nervous); and conscientious (forward thinking, decisive) (Weiss, 2008). Although human personality and hereditary determine the level of human happiness, other factors including environment would still have effects on a human to fill in another part of happiness. So that human can get positive impact from the environment, its stimuli must be pleasantly perceived. Researchers have paid attention to the effects of various stimuli of an environment on mood including environmental scents. With such environmental stimuli, the retailers expect them to improve the customers' mood and potentially increase their loyalty (Rahadi, 2011). A similar study done by Chebat and Michon (2003) concluded that customers' perception of the emotionally pleasing scented mall environment was more positive than that without scent. Also, Bone and Jantrania (1992), as cited by Chebat and Michon (2003) reported that the use of scent to induce customers' mood gave impact to an increase of sales, especially, if its smell was perceptually congruent with the product. Regarding environmental temperature, it was found that its effects on moods were negative as its degree and the humidity inclined (Li, 2014). As this environmental stimulus always relates to the outdoors climatic condition, which people need to consider in carrying out various indoor activities, studies of the effects of a natural environment on moods are always relevant to do. In studying this, Corraliza (2011), reported that nature played a good role in restoring psychological well-being. This notion confirmed Kaplan and Kaplan (1989), as the former author cited, stating that natural habitat was the most effective environment to restore people from work stress.

\subsection{Mood lighting}

Some studies of interior lighting related to moods, well-being or behavior have been done to know what factors of lighting that can give positive impact to the working performance and satisfaction. Many studies of office workers' preference have been done to investigate how static or dynamic lighting support their working throughout the day. McCloughan et al. (1999) researched the combined effects of illuminance levels (high-low) and correlated color temperature (CCT) (cool and warm) to clarify its effect on mood. They found that an interior with a moderate difference in those light variables was supportive for people's moods. A similar study by Knez (1995) and McCloughan et al. (1999) found that lighting with different 
level of color rendering index, the illuminance level, the color temperature had a different impact on people's mood. The different effect also occurs across age and gender difference. Vogels (n. d) found that people's mood, behavior, and well-being can change under the different quality of interior lighting.

Enormous overhead lighting designs have been created to result in various effects of lights. Most studies on lighting related to its positive or negative psychological effect on people confined to those aspects of light. For instance, an experiment by Ciani (2010) aimed to see whether the changing of restaurant colour temperature from a cool color to warmer would give pleasurable effects to the customers. More specific findings on such issue showed that the ambient effect resulted from bright light using an incandescent lamp brought about positive emotion on people (Xu and Labroo, 2013). Wardono et al. (2011) also studied the combination of warm interior lighting, color, and decoration to know its effects on social dining behavior for people dining with a friend compared to that with a special friend. The results showed that the combined effect of a dim lighting using a fluorescent lamp $(5000 \mathrm{Im})$, a monochromatic color scheme and simple décor was supportive for customers' emotion, especially while eating with a special friend.

From this review, it confirms that mood lighting researches concerning the location of light sources seem to be very limited. Therefore, the lights radiating from luminous furniture, which is bellow eye level, is interested in exploring, and we raise some questions as follows. How should furniture be designed so that the light emitting from the bottom of it is effective to stimulate affective response? How should a luminous furniture work regarding its lighting performance to have effects on moods?

\subsection{Methodology}

To run this research we proposed two experiments. The first one aimed to develop a design of illuminated furniture. Some sorts of illuminated furniture were modeled in a kind of lantern. We proposed two lantern variables: form (Square and round) and weaved pattern (Vertical and random) and designed four kinds of lantern resulted from the combination of those variables. These lanterns were presented as the experimental stimulus to 25 respondents aged between, 19-20 (M=19.6) as if it were experienced in a café for gathering subjects' affective response. The ANOVA statistic analysis showed that none of the lanterns gave a different effect on the samples. It meant that any condition of lantern works the same way on the samples' affection $(F(3,96)=.144, p=.933, r=.004)$.

Based on this experiment, we developed two sets of lounge furniture including, four single chairs, two sofas and two tea tables applying rounded form rattan frame and random weaved pattern with translucent polyester fabric cover for conducting the main experiment. An LED strip with specification: Warm white color, OSKA3528-60, voltage: DC 12 V, IP Code: PUIP44, LED/m: 60LED, Power: $1 \mathrm{~m}<=4.8 \mathrm{~W}$, length: $5 \mathrm{~m}$ was applied for the furniture to make it evenly illuminated. Each of this luminous furniture connected to one another and used Arduino software to control the lighting. 

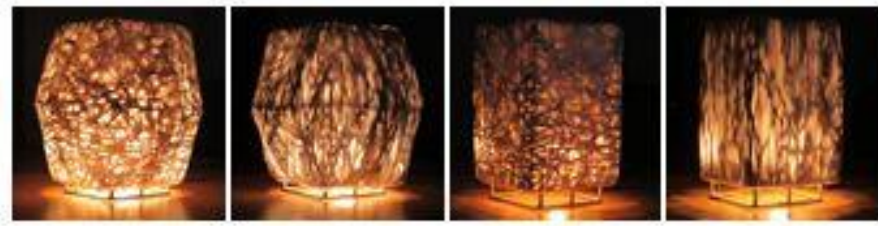

Fig. 1. The stimuli of experiment I include four different kinds of lantern: (a) Rounded form lantern with rounded weaving pattern; (b) Rounded form lantern with vertical weaving pattern; (c) Square form lantern with rounded weaving pattern; (d) Square form lantern with vertical weaving pattern.

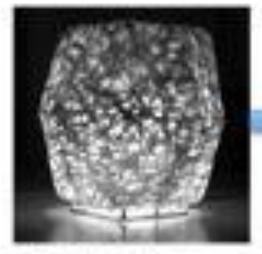

Simd 10 of exteriesnt

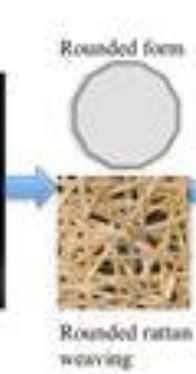

mesving
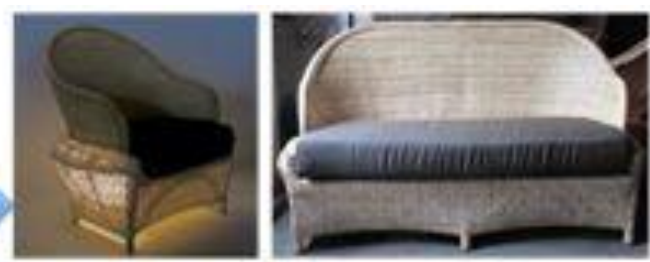

Luminoses chair - -

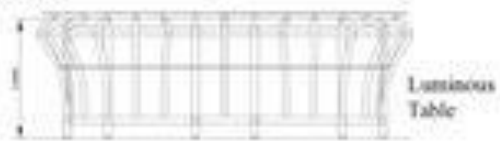

Fig. 2. The design development of luminous furniture

The second experiment applied a quasi-experimental method and took place at one of the dining rooms in "Roemah Kopi" Café, which locates in Rancakendal, Northern area of Bandung, Indonesia. This area is one of a rapidly growing popular culinary shopping destination (Astuti, 2010; Hanan, 2012). In the selection of an experimental dining room, the café owner recommended one that was considered least attractive for the café customers. Because it has no visual access to surrounded landscape, which is important for customers, according to Lawson (2013). However, regarding décor, it still represents the café identity, which is important for respondents' emotional involvement (Ujang, 2010). In the dining room, two sets of luminous lounge chairs and tables were laid out and set up systematically so that three lighting conditions were able to perform as the experimental stimuli. The first lighting condition was the existing or controlled condition, which applied pendant and table lighting fixture using 25 wattages incandescent bulb (See Fig. 3a). The second lighting condition applied the same room, but the pendant lamp was shut off. Whereas all the set of a lounge illuminated furniture was lighted up constantly as high illumination level as 7 Lux average around the table (See Fig. 3b). The third lighting condition applied the same condition as the second one. But the lighting was dynamically set up to three groups of the luminous furniture 
(First group: sofa; second: table; third: single chair). Each of these groups lighted up and dimmed alternately.
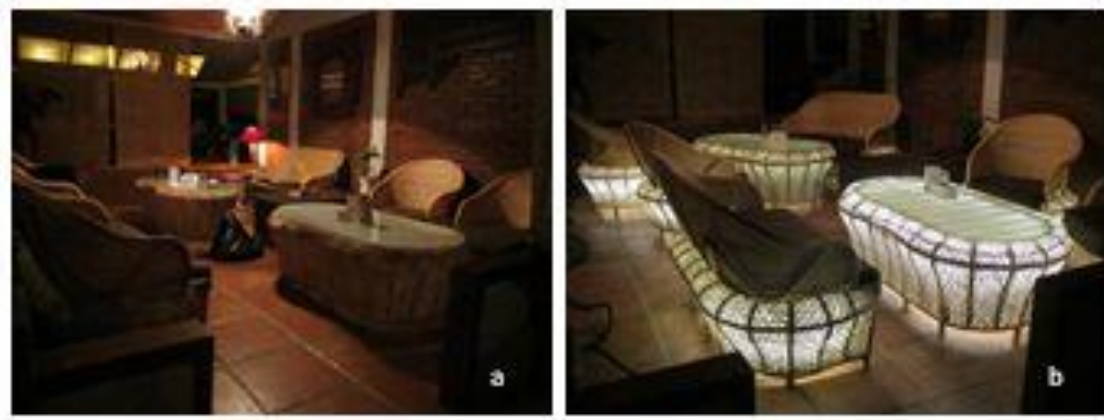

Fig. 3. The stimulus of Experiment 2 involving a room in a café with two sets of luminous lounge chair and tables: (a) The existing room (controlled condition) using pendant and table lighting fixture with $25 \mathrm{~W}$. incandescent lamp and two sets of luminous lounge chair and tables with the lighting application shut off (b) The same room and luminous furniture with the lighting application switched on

Such lighting technique was proposed to refer to the previous research finding that dynamic or pulsating lighting was relevant to the need for positive psychological effect or relaxation (Wan, 2011). A questionnaire to be filled in by the respondents consisted of two types. It included a "mood scale" referring to the emotion scale designed for measuring Positive and Negative Affect Schedule by Watson et al. (1988). It is based on paired items scaling method, such as: cheerful vs. depressing, relaxed vs. tense, calm vs. anxious, etc. The second questionnaire included a "room choice" ruler, by which respondents gave their attitude toward the experimental room atmosphere after reporting their mood. Respondents' intention to choose a manipulated environment was important to know the commercial status of the room (Arifin et al., 2011). Citing Wong (2004), Voon (2011) supported this that there was a positive correlation between emotional quality, which customers felt from a service quality and their loyalty.

To run the experiment 70 students aged between 18-34 (M=22.9) were involved. Before the experiment started, the respondents were asked to browse all other dining rooms to have a general reference of the café. In the middle of the experiment, they were served a glass of beverage for free, in return for their participation. After all the respondents had finished the experiment, the data was then analyzed using statistic ANOVA to compare the samples' response to three different conditions to identify which lighting condition gave significant impact to one another.

\subsection{Findings and Discussions}

From the data analysis, it shows that there are significant differences in the samples' mood response toward some lighting conditions $(F(2,207)=75.239, p=.000, r=.421)$. The 
samples' mood response toward the second lighting condition is significantly different to that in the first and third lighting condition. Also, the samples' response toward the existing lighting condition is also different significantly from that toward the third lighting condition. This finding clearly shows that the samples' response toward the constant mode of the lighting of the luminous furniture is most effective to support the samples' mood. In other words, the existing room lighting using pendant lamp, which is above eye level, or the dynamic lighting of luminous furniture seems not suitable for supporting the samples' mood. Surprisingly, a dining room with light effect radiated primarily from below eye level is found effective to improve affection. As well, it also supported the samples' intention to choose this room for dining, although the lighting illumination level around the tea table was very low or average: 7 Lux. This fact indicated that it sufficiently supported the guests to see each other and enjoy such atmospheric quality. This evidence also clarifies the study by (1995) and McCloughan et al. (1999) that different level of illumination has an effect on mood. As well, this finding also reconfirms the study by Vogels $(n d)$ that different quality of lighting can change people's mood

\subsection{Conclusion}

We can conclude that the luminous furniture using rounded form furniture, random weaved pattern and polyester jersey fabric cover is effective to support the samples' mood. Especially when its lighting fixture works in a constant mode or not in a dynamic setting. Besides, such positive effect on people's affection may also relate to the warm look of rattan material, and cotton fabric used as its cover. This appearance might also reconfirm why Asian lanterns made from bamboo and paper have been in use along with their traditional culture. This result also supports the fact that people prefer a human material or environment, and the need for this is increasingly critical said Khan (2013).

These new findings complements to the theory that people not only prefer to look at a brighter area but interestingly they also enjoy sitting in a brighter area illuminated from below or on a luminous furniture. The negative response of the samples towards the dynamic luminous furniture seemed related to their problem in observing the meal during dining, especially when the lighting was dimming. However, the effects of a luminous furniture on the beverages especially the juice drinks appearance are even interesting because of its transparent and colored glasses, and therefore, more appealing, than if they are illuminated from above eye level.

For future research, a variable of color rendering of lighting fixture for luminous furniture could be studied for exploring further expectation of dining, since LED strips provide RGB color, and the lighting operation of each LED color can also be controlled automatically.

This research may give a new insight in how a lighting and behavior research is conducted. Especially how light is manipulated by integrating a lighting fixture to furniture since the latest lighting technology allows us to put it in a more limited space and need less energy. Therefore, in the future, a similar way of research by looking at how light is 
coordinated with other elements in an interior space could be considered and explore its effect on human. Thus, further explanations on the role of light for better quality of life could be strategically anticipated. We expect that by considering a further integration of light with interior elements, the implications of research to design education and profession could be more promising. As well, as we could predict innovative lighting designs more scientifically, the product development would hopefully be more successful.

\section{Acknowledgement}

We conducted this research with financial support from the Indonesian Government through the Directorate of Higher Education; therefore, we are grateful for their contribution. A special thank dedicates to Roemah Kopi café, Bandung for making this research project possible.

\section{References}

Ciani, A.E. (2010). A Study of How Lighting Can Affect a Guest's Dining Experience. Unpublished Master's Thesis, lowa State University, Ames, lowa, USA.

Chebat, J.C \& Michon, R. (2003). Impact of Ambient Odors on Mall Shoppers' Emotions, Cognition, and Spending A Test of Competitive Causal Theories. Journal of Business Research, 56, 529-539.

Khan, S. (2013). Research-Practice Paradigm: An Asian Perspective. Paper presented in Asia Pacific International Conference on Environment-Behaviour Studies. Doi:10.1016/j.sbro.2013.11.005

Knez, I. (1995). Effects of Indoor Lighting on Mood and Cognition. Journal of Environmental Psychology, 15(1), 3951.

Lawson, B. (2013). Design and Evidence. Paper presented at Asia Pacific International Conference on EnvironmentBehaviour Studies, doi:10.1016/j.sbspro.2013.11.004

Li, G. (2014). Effects of Human Mood State in Extreme Hot Environment. Applied Mechanics and Materials, 522$524,541-543$.

McCloughan, C.L.B., Aspinall, P.A., \& Webb, R.S. (1999). The impact of lighting on mood. Lighting Research Technology. 31 (3), 81-88.

Rahadi, R.A. (2011, June 15-17). Factors Related to Repeat Consumption Behaviour: A Case Study in Traditional Market in Bandung and Surrounding Region. Paper presented at the Proceedings of ASEAN Conference on Environment-Behaviour Studies. doi: 10.1016/j.sbspro.2012.03.058.

Veitch, J.A. (2001). Psychological Processes Influencing Lighting Quality. Journal of Illuminating Engineering Society. $30,124-140$

Vogel, I. (n.d). Atmospheric Metrics: Development of a tool to quantify experienced atmosphere in Westerink et al. (Eds.), Probing Experience (pp.25) 
Wardono, P., \& Nugroho Soelami, F.X. / Asian Journal of Quality of Life (AjQoL), 3(10)) Mar / Apr 2018 (p.69-77)

Vosburg, S.K. (1998). The Effects of Positive and Negative Mood on Divergence -thinking. Creativity Research Journal, 11(2), 165-172.

Wan, S.H. ( 2011). An Explorative Study of the Effect of Lighting on Stress-recovery. Unpublished master's thesis, Eindhoven University, The Netherlands performance.

Watson, D., Clarck, L.A., \& Tellegen, A. (1988). Development and Validation of Brief Measures of Positive and Negative Affect: The PANAS Scales. Journal of Personality and Social Psychology, 54(6), 1063-1070.

Weiss, A., Bates, T.C., \& Luciano, M. (2008). Happiness is a Personal(ity) Thing: The Genetics of Personality and Well-being in a Representative Sample. Psychological Science, 19, 205-10

Xu, A.J. \& Labroo, A.A. (2013). Incandescent Affect: Turning on the Hot Emotional System with Bright Light. Journal of Consumer Psychology, 24, 207-216. 